and generates pressure ripple. FBNS is a very interesting source to tackle since pressure variations propagate through the lines and interact with mechanical parts and air leading to further structure borne noise and air borne noise. The integration of units and hydraulic line opens the possibility to minimize FBNS both through units and system design. Computational design is a great tool for this application, and it requires models with good prediction and parameterization of the noise sources.

In respect to unit design, FBNS reduction already was successfully obtained for many types of positive displacement units such as axial-piston [3], external gear [4] and vane units [5]. The computational evaluation and minimization of noise sources by tuning hydraulic lines was also studied but has been bounded by the limitations of the current line models.

Akers et al. [6] obtained noise reduction with lumped parameter techniques analogous to electrical systems where fluid pressure is comparable to voltage and fluid flow is comparable to current. However, the precision of the lumped parameter technique is very limited.

The most popular approaches for modelling lines are based on transmission line method (TLM) which relies on the frequency superposition principle to accurately predict the propagation of vibrations in a hydraulic circuit. Advances have been done in respect to the TLM approach including the estimation of frequency dependent friction achieving good accuracy for simple straight lines [7-9]. The extension of this efficacy for more complex lines still in progress.

In respect to FBNS reduction, transfer matrix techniques were used to tune parallel lines [10] and side branch silencers [11]. However, in the latter study, the insertion loss of the side-branch-based silencer was strongly dependent on the influence of the upstream and downstream elements.

As long as the sources, sinks and lines frequency responses are well understood, transfer matrix approaches are well capable of predicting the superimposed pressure and flow pulsations [12]. However, the need of experimental characterization of the hydraulic elements still pose a drawback for achieving FBNS reduction using transfer matrix approaches, just like the accuracy limitations for complex lines.

Finite element based models were also capable of calculating superimposed noise sources based on the interaction among pump, motor, and line dynamics. The two most common approaches are the Garlekin method and method of characteristics (MOC) being the MOC the most accurate one [13].

The method of characteristics was developed in order to predict for the transients in pipe, mainly focused in the water-hammer effect present in when opening hydraulic lines [14]. When opening the valve in the line, the sudden flow variation of the fluid meets the momentum of the fluid in its respective downstream generating a rapid pressure rise. This pressure rise can harm several hydraulic components, thus becoming an issue and a motivation to develop models capable of predicting these phenomena accurately considering steady and unsteady wall shear stress suitable in both laminar and turbulent regimes [15-17].

In respect to minimizing $\mathrm{FBNS}$, the $\mathrm{MOC}$ method was used by Klop [18] to demonstrate the impact of line length on noise sources. However, with respect to accuracy, the same model obtained far better results predicting pressure oscillations in a controlled noise-source guided experiment than in a real transmission [19]. In the model, the speed of the wave propagation would remain constant within the whole extent of the line not accounting for positional characteristics of the line such as diameter variations and curvatures.

Both transfer matrix and finite element methods still strive for precision and accuracy to replicate FBNS behavior in sophisticated line architectures and there is still room for improvement for both. Predicting pressure oscillations accurately with a non-empirical model is still a challenge to be surpassed in order to achieve FBNS reduction in hydraulic circuits through computer assisted design. Time domain methods, however, already been successful validated for unit design and these models can be coupled and integrated with a time domain line model more easily than transfer matrix ones.

A lot of research was conducted in order to reduce noise and noise sources in hydraulic circuits. There are many strategies to achieve this reduction such as Active techniques using as piezo-electric [20] and valve [21] actuators, passive elements techniques using hydraulic line elements such as closed-branch silencers [22] expansion chambers [23] actuators and also vibration absorbing techniques $[24,25]$. Nevertheless, in order to project systems which are inherently quiet, line modelling advances are still needed.

The models still need to consider curvatures, diameter changes, line discontinuities and account for operation conditions nuances such as temperature, pressure and fluid aeration variations, it is still necessary to develop better models that are capable of accurately describing the system behavior. These difficulties arrive in the example of the hydraulic transmissions, which this study focuses on. While HTs are the simplest hydraulic drive circuit and yet is very commonly used in current technology, noise reduction for transmissions is rather difficult.

This study presents a MOC modelling strategy for coupled system noise source prediction and validation in a system without characterized sources and sinks. The high pressure line model considers realistic discontinuities 
such as curvatures, duct diameter and duct material variation. Fluid properties impact on FBNS are evaluated.

\section{The modelling approach}

\subsection{Model and assumptions}

The model developed on this work is a transmission model where two lumped parameter swash-plate type axial piston unit models are coupled with a onedimensional fluid flow line model with discretized duct parameters.

Figure 1 describes a hydrostatic transmission with the modeling being focused at the high pressure line. Unit models have pressure, unit displacement and speed as inputs. Units have displacements ${ }_{1}$ and ${ }_{2}$ set at $100 \%$ the respective unit size. Speeds $n_{1}$ and $n_{2}$ are also inputs for the lumped unit model. Unit 1 (pumping) shaft speed is set and unit 2(motoring) speed is determined by the transmission volumetric losses. Transmission dynamics determines unit 2 speed and the mean pressure at line $A$.

The line model is unidimensional which limits its spatial physical representation. The goal of this model is to understand the impact of parameters on fluid vibrations translating in the fluid path. Structural propagating waves and coupling boundary conditions are a further goal for this project, some assumptions were made for the modelling. The most important assumptions of this work are:

a. The fluid is viscous, compressible, isotropic, and its motion is axially symmetric.

b. The temperature variations are small enough so that the oil and material properties can be considered constant with respect to temperature during simulation.

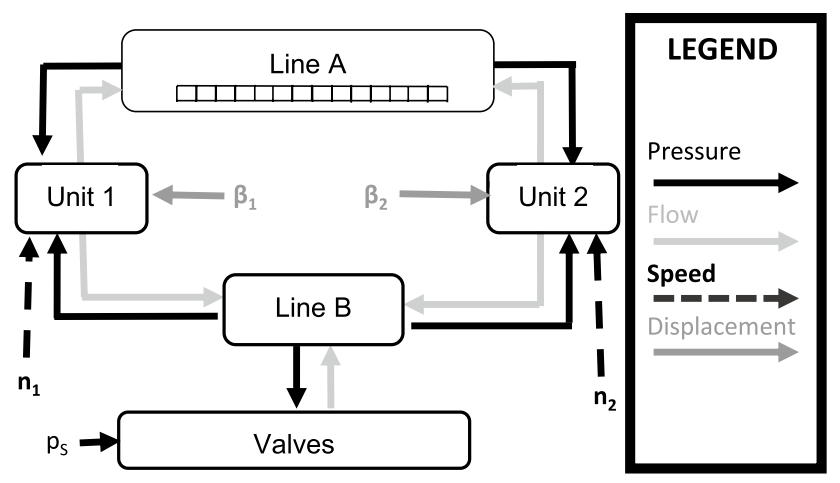

Fig. 1 Hydraulic system model block diagram c. Friction has a steady component and a frequency dependent component

d. There is no asymmetric vibration propagating from the hydraulic units to the couplings connected through the mechanical path

e. Only vibrations propagating through the fluid are evaluated. Integration with structural vibration is a good topic for future work.

\subsection{Line model}

A fixed time step discrete line model is developed based on the method of characteristics approach of which develops a one-dimensional grid compressible fluid flow line model [14]. The model is developed based on the quasisteady hyperbolic differential equations which describe the principles of conservation of fluid flow momentum (1) and continuity (2).

$L 1=\cdot \frac{1}{\rho} \frac{d p}{d z}+\frac{d v}{d t}+\frac{2}{\rho \cdot r} \tau=0$

$L 2=\frac{d p}{d t}+\rho c^{2} \cdot \frac{d v}{d z}=0$

The variable $p$ indicates pressure; $v$ represents the fluid velocity in the $z$-direction of pipe length while the mass density of the fluid is given by $\rho$. The wave speed of the continuity equation $c$ is the speed of sound, $\tau$ is the shear stress between fluid and duct wall and the internal radius of the conduit is given by $r$. The method of characteristics develops equations (1) and (2) into four ordinary differential equations called characteristic equations. These four equations are solved through the application of boundary conditions using a fixed time step and discretizing the line into several nodes. The line node parameters are shown in Fig. 2.

The result is the transformation of two discrete characteristic equations which describe the pressure build-up in the positive $(C+)$ and negative $(C-)$ directions on the $z$ axis. The

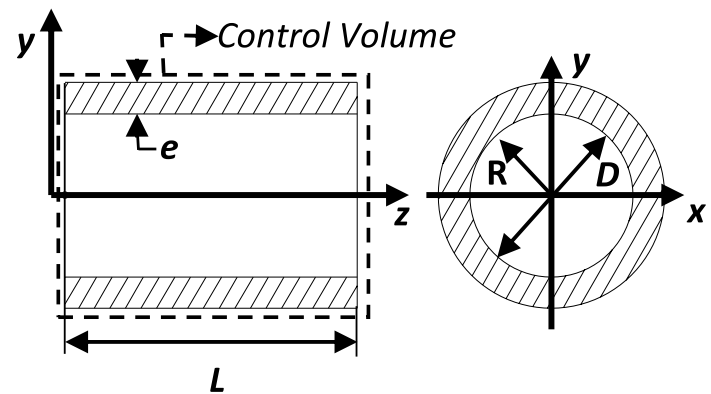

Fig. 2 Duct parameters for a single node at the line 
equations are shown in (3), (4) and (5) where $r$ is the inner radius of the line, $A_{j}$ is the inner pipe area, $B_{j}$ is the isothermal wave speed and the flows are denoted by $Q$.

$C_{P}=p_{j-1}+B_{j} \cdot Q_{j-1}-\frac{2 \cdot \Delta z \cdot \tau_{j-1}}{r}$

$C_{M}=p_{j+1}+B_{j} \cdot Q_{j+1}+\frac{2 \cdot \Delta z \cdot \tau_{j+1}}{r}$

$B_{j}=\frac{\rho C}{A_{j}}$

The flow for inner nodes is calculated after the pressure, as a function of the pressure difference between each node and the isothermal wave speed $\mathrm{B}_{\mathrm{j}}$. Flow components traveling on the positive and negative directions are calculated and the updated node flow is determined as the average of the two (6). The flows at the boundaries are the inputs of the model and are updated at every time step.

$Q_{j}=\frac{1}{2}\left(\frac{C_{p}-p_{j}}{B_{j}}+\frac{p_{j}-C_{m}}{B_{j}}\right)$

The speed of sound $c$ of a slightly compressible fluid confined in an elastic conduit can be derived according to (7) [26]. The pressure wave speed will depend on the oil properties such as mass density of the fluid and bulk $\operatorname{modulus}(K)$, and also upon the elastic properties of the conduit and external constraints. Elastic properties include the conduit diameter $D$, wall thickness $e$, and wall material Young modulus $E$.

$c=\frac{\sqrt{\frac{K}{\rho}}}{\sqrt{1+\psi \frac{K}{E}}}$

The variable $\psi$ is influenced by the type of support and the freedom of pipe longitudinal movement since the axial movement of the conduit will result also in a longitudinal displacement proportional to the Poisson ratio $\mu$. For a thin walled duct, the values of $\psi$ are given by equations: a) Pipe anchored at upstream only (8) b) Duct anchored at both ends (9) c) Pipe with expansion joints in both ends (10).

$\psi=\frac{D}{e}(1-\mu / 2)$

$\psi=\frac{D}{e}\left(1-\mu^{2}\right)$

$\psi=\frac{D}{e}$

\subsection{Hydraulic unit modelling}

The positive displacement unit lumped parameter approach based in the orifice equation and the compressibility continuity equation is well known and was validated for several models of units such as swash-plate axial piston [27], external gear [28] and linkage units [29]. The model is briefly summarized in this section, for further detail refer to [27]. A simplified schematic of the major model components is represented by Fig. 3.

In a swash-plate type axial piston pump, the rotating group parts consist of the cylinder block, slippers, slipper retainer, pistons and the shaft. As the cylinder block rotates, each piston goes back and forth causing a displacement of fluid inside the displacement chamber (DC) resulting in intake and outtake flow. At pumping operation, the great majority of intake and outtake flow will be on the low pressure (LP) and high pressure (HP) ports respectively

The displacement chamber pressures constitutes a critical parameter to predict fluid borne noise. Each displacement chamber is considered to be a control volume and its pressure is calculated with respect to time based on the explicit numerical method. The Euler method was chosen to update the pressures by using the value of the pressure in the previous time step $p_{k}$, step size $h$ and pressure variation $\Delta p(11)$.The value of $\Delta p$ found by calculating the pressure buildup equation(12) in the previous instant of the simulation. The equation is based on the principle of mass conservation and evaluate the pressure gradient one the base of the net flow to the chamber as well as the variation of the chamber volume. The volume of each chamber $i$, is given by the volume $V_{\mathrm{i}}$.

$p_{k+1}=p_{k}+h \cdot \Delta p=p_{k}+h \cdot \frac{\partial p_{i}}{\partial t}$

$\frac{\partial p_{i}}{\partial t}=\frac{K}{V_{i}}\left(Q_{r i}-Q_{S K i}-Q_{S B i}-Q_{S G i}-\frac{\partial V_{i}}{\partial t}\right)$

The flows $Q_{\mathrm{SKi}^{\prime}} Q_{\mathrm{SBi}}$ and $Q_{\mathrm{SGi}}$ occur respectively at interfaces between the piston and the cylinder block, between the cylinder block and the valve-plate, and between the piston

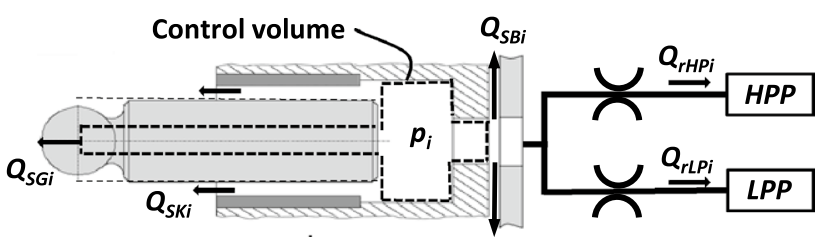

Fig. 3 Simplified axial piston unit displacement chamber schematics 
and the slipper. These leakages will result in volumetric losses for the unit which are calculated using a loss model developed experimentally.

The flow $Q_{\text {Sri }}$ is the summation of flow entering and exiting the chamber through the high pressure port (14) and low pressure port (15). Both these terms are calculated based on the orifice equation. The orifices $A_{\mathrm{rHP}}$ and $A_{\mathrm{rLP}}$ are equivalent to the smallest cross-sectional opening areas between the displacement chamber pressure ports in a given instant of time and $\alpha_{D}$ is the coefficient of discharge. The cross-sectional areas are mainly given by the geometry of the valve-plate present in the unit.

$Q_{r i}=Q_{r H P i}+Q_{r L P i}$

$Q_{r H P i}=\alpha_{D} \cdot A_{r H P i} \sqrt{\left|p_{i}-p_{H P}\right|} \cdot \operatorname{sign}\left(p_{H P}-p_{i}\right)$

$Q_{r L P i}=\alpha_{D} \cdot A_{r L P i} \sqrt{\left|p_{i}-p_{L P}\right|} \cdot \operatorname{sign}\left(p_{L P}-p_{i}\right.$

\section{Experimental setup}

For model validation, the experimental setup shown in Fig. 4 was assembled at Maha Fluid Power Research Center of Purdue University using two Sauer Danfoss 590 swash plate axial piston type positive displacement units. The pumping and motoring units were respectively sized at $42 \mathrm{cc}$ and $75 \mathrm{cc}$. This transmission was derived from the works of Sprengel et al [30] and specifically used at the works of Williams and Ivantysynova [31]. This design is focused on mid-power, high density hydraulic functionalities for road vehicle applications, which have strict noise regulations.

The supply line (Line S) is set at 24 bar. The transmission test circuit has the ability to demonstrate three different architectures depending on the state of the enabling valves: If all three enabling valves are closed the circuit is a hydrostatic transmission (HST), By opening valves 1 and 2 the series hybrid transmission ( $\mathrm{SH}$ ) is achieved. The third configuration is called mode switching hybrid (MSH), which is an architecture able to manage energy consumption efficiently.

Table 1 describes the hydraulic components used in the circuit while Table 2 shows information concerning sensors and type, range and accuracy of the electronic equipment. The accuracy can be quantified by the default measuring unit, measured value (MV) or full scale (FS). Steady-state operation conditions were assured by installing thermocouples in the high-pressure line $\left(T_{a}\right)$, low-pressure line $\left(T_{b}\right)$ and the drain line $\left(T_{d}\right)$. In order to quantify the pressure oscillations in the hydraulic circuit, three Kistler 603B1 piezoelectric sensors were installed in Line A to measure local dynamic pressure and sampled at 20000 cycles per second

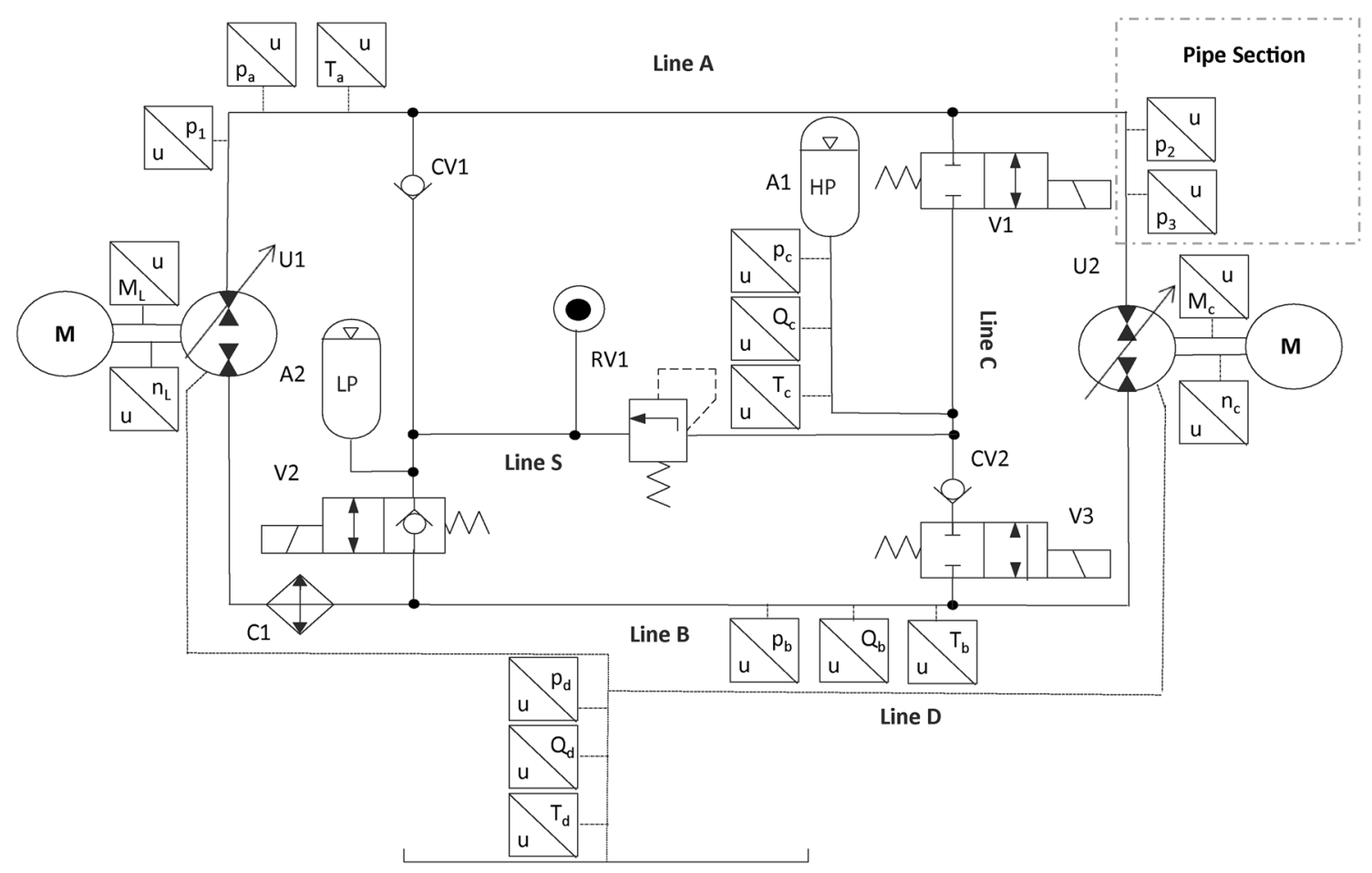

Fig. 4 Hydraulic Schematic of the experimental setup 


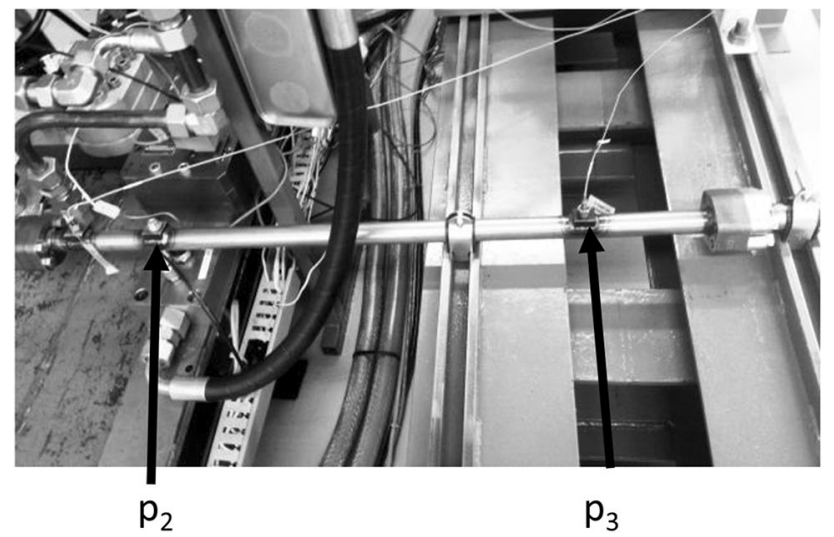

Fig. 5 Steel pipe with $25.4 \mathrm{~mm}$ inner and 31.7. $\mathrm{mm}$ outer diameter

Table 1 Hydraulic circuit components

\begin{tabular}{ll}
\hline Tag & Hydraulic component \\
\hline A1 & Low pressure accumulator \\
A2 1 & High pressure accumulator \\
CV1 & Cooler \\
CV2 & Check-valve 1 \\
RV1 & Check -valve 2 \\
V1 & Relief valve \\
V2 & Enabling valve 1 \\
V3 & Enabling valve 2 \\
U1 & Enabling valve 3 \\
U2 & 42 cc swash-plate unit \\
\hline
\end{tabular}

Table 2 Electronic sensors

\begin{tabular}{lll}
\hline Tag & Sensor & Range $\mid$ Accuracy \\
\hline $\mathrm{p}_{a}$ & Pressure: Piezo-resistive & $0-400 \mathrm{bar} \mid \pm 0.1 \% \mathrm{FS}$ \\
$\mathrm{p}_{b}$ & Pressure: Piezo-resistive & $0-345 \mathrm{bar} \mid \pm 0.1 \% \mathrm{FS}$ \\
$\mathrm{p}_{c}$ & Pressure: Piezo-resistive & $0-552 \mathrm{bar} \mid \pm 0.1 \% \mathrm{FS}$ \\
$\mathrm{p}_{d}$ & Pressure: Piezo-resistive & $0-25 \mathrm{bar} \mid \pm 0.2 \% \mathrm{FS}$ \\
$\mathrm{p}_{s}$ & Pressure: Piezo-resistive & $0-60 \mathrm{bar} \mid \pm 0.1 \% \mathrm{FS}$ \\
$\mathrm{p}_{1}$ & Pressure: Piezo-electric & $-30-30 \mathrm{bar} \mid \pm 0.4 \%$ bar FS \\
$\mathrm{p}_{2}$ & Pressure: Piezo-electric & $-30-30 \mathrm{bar} \mid \pm 0.4 \%$ bar FS \\
$\mathrm{p}_{3}$ & Pressure: Piezo-electric & $-30-30 \mathrm{bar} \mid \pm 0.4 \% \mathrm{bar} \mathrm{FS}$ \\
$\mathrm{T}_{a}$ & Type K thermocouple & $0-480{ }^{\circ} \mathrm{C} \mid \pm 0.75 \% \mathrm{FS}$ \\
$\mathrm{T}_{b}$ & Type K thermocouple & $0-480{ }^{\circ} \mathrm{C} \mid \pm 0.75 \% \mathrm{FS}$ \\
$\mathrm{T}_{d}$ & Type K thermocouple & $0-480{ }^{\circ} \mathrm{C} \mid \pm 0.75 \% \mathrm{FS}$ \\
$\mathrm{Q}_{c}$ & Flowmeter & $1-250 \mathrm{l} / \mathrm{min} \mid \pm 0.3 \% \mathrm{MV}$ \\
$\mathrm{Q}_{b}$ & Flowmeter & $1-250 \mathrm{l} / \mathrm{min} \mid \pm 0.3 \% \mathrm{MV}$ \\
$\mathrm{Q}_{d}$ & Flowmeter & $0.1-120 \mathrm{l} / \mathrm{min} \mid \pm 0.3 \% \mathrm{MV}$ \\
$\mathrm{M}_{e}$ & Torquemeter & $500 \mathrm{~N} \mathrm{~m} \mid \pm 0.1 \% \mathrm{~N} . \mathrm{m}$ \\
$\mathrm{M}_{L}$ & Torquemeter & $500 \mathrm{~N} \mathrm{~m} \mid \pm 0.1 \% \mathrm{~N} . \mathrm{m}$ \\
$\mathrm{n}_{e}$ & Tachometer & $0-12000 \mathrm{rpm} \mid \pm 0.1 \% \mathrm{rpm}$ \\
$\mathrm{n}_{L}$ & Tachometer & $0-420 \mathrm{~Hz} \mid \pm 0.01 \% \mathrm{~Hz}$ \\
\hline
\end{tabular}

Table 3 Line features position relative to the source

\begin{tabular}{lll}
\hline Feature & Positon 1 $(\mathrm{mm})$ & Positon 2 $(\mathrm{mm})$ \\
\hline Steel section & $0-220$ & $1220-2950$ \\
Hose section & $220-1220$ & $2950-3880$ \\
Elbow & $1240-1340\left(90^{\circ}\right)$ & $1390-1450\left(90^{\circ}\right)$ \\
Diameter & Default $(19 \mathrm{~mm})$ & $1240-1340(15 \mathrm{~mm})$ \\
$\Delta$ p Sensors & 140 & 2020 \\
Feature & Positon 3 $(\mathrm{mm})$ & Positon 4 $(\mathrm{mm})$ \\
Steel section & $3880-3930$ & - \\
Hose section & - & - \\
Elbow & $1510-1570\left(90^{\circ}\right)$ & $1570-1780\left(12^{\circ}\right)$ \\
Diameter & $1970-2780(25 \mathrm{~mm})$ & - \\
$\Delta$ p Sensors & 2770 & - \\
\hline
\end{tabular}

Table 4 Operation conditions

\begin{tabular}{llll}
\hline Test & U1 Speed (rpm) & Mean HP (bar) & Mean LP (bar) \\
\hline A & 2000 & 100 & 24 \\
B & 2000 & 200 & 24 \\
C & 2000 & 300 & 24 \\
D & 3000 & 100 & 24 \\
E & 3000 & 200 & 24 \\
\hline
\end{tabular}

$(20 \mathrm{kHz})$.This sensors can operate in pressures up to 1000 bar and have a range of negative to positive 20 bar oscillation. Sensor 1 was positioned as close as possible of the outlet of the pumping unit. Sensors 2 and 3 were placed in a steel pipe 720 millimeters apart from each other. Sensor 3 is placed 118 millimeters before unit 2 intake. The latter two piezo-electric pressure sensors were installed in a steel pipe demonstrated by Fig. 5 .

The steel pipe line section has constant and well known parameters, thus is used to measure the speed of sound as described later. Hydraulic line A has hydraulic hoses and steel segments and fittings throughout its length. Also, there were three sharp elbows in the line. Duct inner diameter varied from 15.0 to 25.4 millimeters along the line. The hydraulic line has a total length of 3.93 meters and it is detailed on Table 3.

Five operating conditions were achieved by operating the hydraulic circuit as a hydrostatic transmission and setting a constant speed of Unit 1. Load simulator torque was adjusted manually in order to achieve the target pressure in Line A. Unit 2 speed was set reactively by the operation condition and volumetric efficiency of the units. Both units were set at $100 \%$ displacement. The testing was performed with an inlet temperature of $52^{\circ} \mathrm{C}$ at steady state. Figure 6 shows pictures of the test rig.

Table 4 shows the five operation conditions which were tested. Since the axial piston unit used for this experiment 


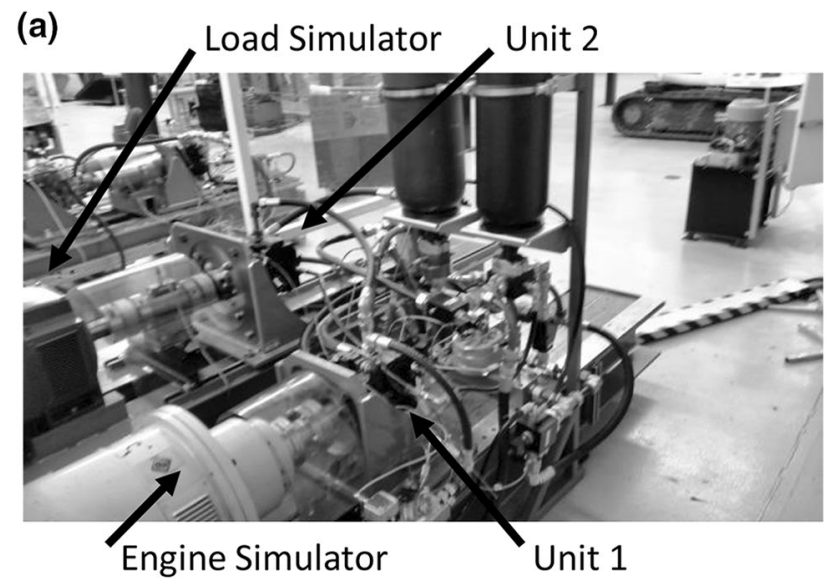

(b)

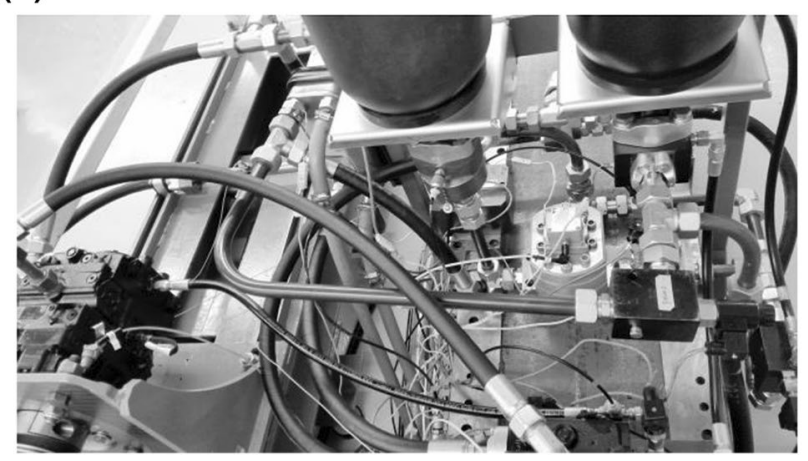

Fig. 6 Hydraulic transmission experimental setup side view (a) and top view (b)

has nine pistons the frequency harmonics of the oscillations will be multiples of $300 \mathrm{~Hz}(2000 \mathrm{rpm})$ and $450 \mathrm{~Hz}$ (3000 rpm). In axial piston units most of the energy content are in the first two harmonics, however even higher frequency content such as the $17^{\text {th }}$ harmonic can generate noticeable noise [32].

\section{Oil parameters influence}

\subsection{Bulk modulus influence}

The model updates oil density and bulk modulus at each time step. This study used a SAE 32 petroleum-based oil and measured its density and isothermal bulk modulus as functions dependent on temperature and pressure. The mathematical model is based on a five variable interpolant where the coefficients can be calculated by measuring the parameters change in respect to varying temperature/constant pressure and varying pressure constant temperature. The reference temperature was chosen to be $25^{\circ} \mathrm{C}$ and the reference pressure was set at 1.03 bar. The reference density was measured as $843.3 \mathrm{~kg} / \mathrm{m}^{3}$.
The assumption of isothermal bulk modulus is popular choice in the fluid power field, to model the pressure evolution is hydraulic systems. This means that in most cases, even if the process is closer to be adiabatic, the effects of fluid temperature variations are negligible with respect to those due to pressure variations. However, since noise source pressure oscillations in hydraulic systems occur very rapid, leaving no time for heat dissipation, adiabatic bulk modulus may be more suitable for describing FBNS.

The tangent isothermal bulk modulus $\left(K_{\mathrm{T}}\right)$ can be converted to the tangent adiabatic bulk modulus $\left(K_{\mathrm{S}}\right)$ due to its association to isobaric $\left(s h_{\mathrm{p}}\right)$ and isochoric $\left(s h_{\mathrm{v}}\right)$ specific heats of the fluid element(16). This relationship is obtained using the thermodynamic Maxwell relations [33, 34].

$\frac{K_{S}}{K_{T}}=\frac{s h_{p}}{s h_{v}}$

$$
=\frac{0.13+0.015 \log \left(v\left(p_{A t m^{\prime}}, 20^{\circ} \mathrm{C}\right)\right) 10^{4+\frac{20-T}{435}}+5.6 p_{g}}{0.157+0.015 \log \left(v\left(p_{A t m^{\prime}}, 20^{\circ} \mathrm{C}\right)\right) 10^{4+\frac{20-T}{417}}+5.6 p_{g}}
$$

, The specific heat ratio is assumed to be similar to $\mathrm{H} 68$ oil, for which equation (16) can be derived from the work of Hayward [34].

\subsection{Aeration influence}

Besides the line discontinuities influence on pressure ripple, the fluid properties can also impact on fluid borne noise. Bulk modulus is the property which governs fluid pressurization and also has a major effect on wave speed. One factor which affects the oil properties is fluid aeration. Some of the models to calculate the effective bulk modulus after air influence are the Wylie, Nyknen and IFAS models [35]

While this study is based in closed circuit operations, fluid models capable of evaluating the effects of aeration are even more important in open circuit and low pressure applications due the effects of cavitation, when the air content influences the fluid behavior much further. Models such as the Full Cavitation Model [36] and the model developed by Belamri [37] are worth mentioning.

An effective bulk modulus model which accounts for wave speed change caused by aeration is the model described by Huayong et al. [38]. The model given by equation (18) and (19) accounts for dissolved and entrapped air which will change with fluid pressurization.

$K_{\text {eff }}=\frac{1}{-\alpha p_{0} K_{\text {oil }}\left(\frac{1}{p}\right)^{2}+A\left(\frac{1}{p}\right)+1-\alpha} K_{\text {oil }}$

where 
$A=-10 \delta_{0} p_{0} K_{\text {oil }} \cdot \alpha^{2}$

The volumetric air content in the air-oil mixture is given by $\alpha$ and the air solubility of hydraulic fluid at atmospheric pressure and room temperature, also called the Bunsen coefficient, is given by $\delta_{0}$.

\subsection{Air content estimation}

In order to evaluate the impact aeration has on FBNS in closed circuit hydraulic systems it is necessary first to estimate the amount of air present in the experiment described previously. Since the pipe section between piezoelectric sensors 2 and 3 is well defined and has constant parameters, the speed of sound is considered to be constant in this respective line segment.

As both bulk modulus and density will be influenced by the air content in the oil, the speed of sound of a pressure wave propagating in the fluid will also be altered. Using equation (7) and knowing the geometry of the steel pipe used in the experiment, the speed of sound for different air content proportions can be back-calculated at the default pressures of the experiments: 100, 200 and 300 bar. The wave speed behavior is shown in Fig. 7.

As the pressure ripple originating in the pumping unit translates in the positive direction, the same oscillations will influence the pressure ripple in the sensor 3 position with a delay with respect to its distance from the sensor in the previous position. Two popular techniques to verify the relationship of both signals are the cross-correlation, which quantifies the linearity between both signals, and the cross-variance, which quantifies the linearity of the variation of both inputs. Equation (20) shows the covariance

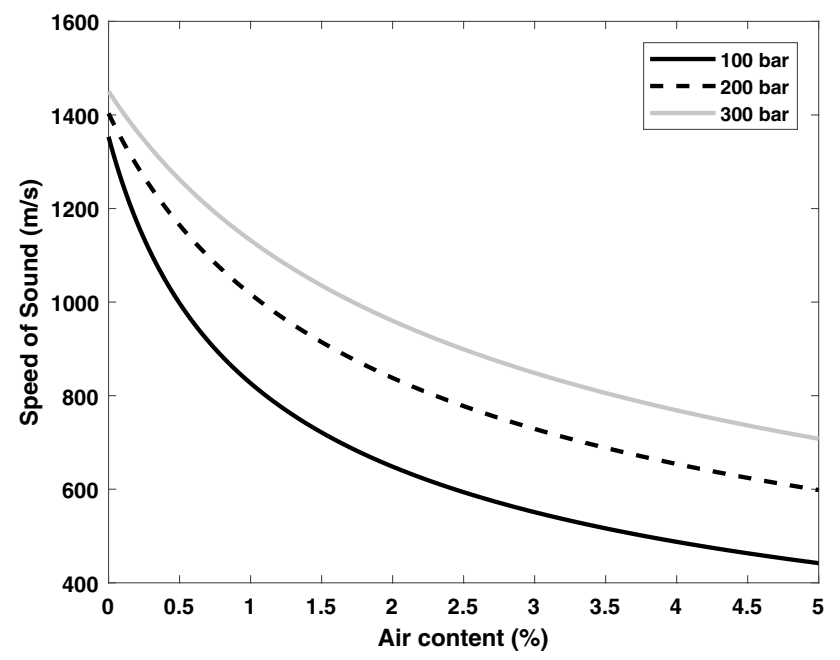

Fig. 7 Speed of sound influenced by air content in a steel pipe with $25.4 \mathrm{~mm}$ internal diameter and $31.75 \mathrm{~mm}$ external diameter for an $N$ point sample of both piezoelectric sensor signals. The delay is given by $k$ and the averages of the signals are given by $\mu$.

$\operatorname{Cov}\left(p_{2}, p_{3}, k\right)=\frac{\sum_{i=1}^{N}\left(p_{2, i+k}-\mu_{p 2}\right)\left(p_{3, i}-\mu_{p 3}\right)}{N-1}$

Therefore, by introducing the delay $k$ on sensor 2 it is possible to verify which delay has the largest covariance. As the sampling of the piezoelectric sensors are synchronized and rated at $20000 \mathrm{kH}$, the corresponding wave speed of each delay $k$ is given by (2).

$c_{k}=20000 \frac{0.72}{k}$

The covariance was verified for speeds from 0-3000 m/s. Due to the relatively low sampling rate of the sensors compared to the delay, a $6^{\text {th }}$ order polynomial was used to calculate the speed which achieved maximum covariance. As shown in Fig. 8, the speed of sound was estimated approximately equal to 1175,1229 and $1283 \mathrm{~m} / \mathrm{s}$ for 100 , 200 and 300 bar pressure respectively, obtained from Tests $A, B$ and $C$.

Thus, based on Figs. 7 and 8, the volumetric entrained air amount in oil was calculated as equal to $0.19,0.34$ and $0.43 \%$ respectively for 100,200 and 300 bar. For the next
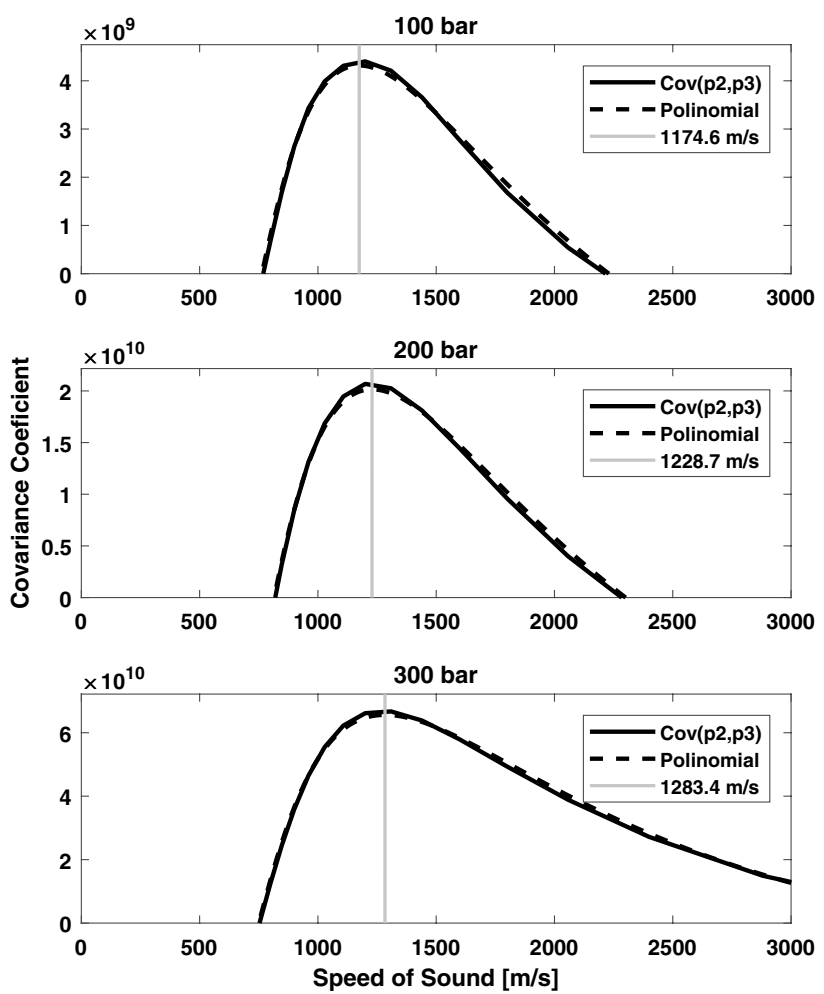

Fig. 8 Wave speed estimation for 100, 200 and 300 bar 
section oil parameter impact on simulation was evaluated considering isothermal, adiabatic and aerated adiabatic oil properties on the simulation and comparing it to measurement. A possible justification for higher air content in higher pressures is that with a higher pressure difference, more air from the low pressure side can be dissolved, and preserved in the fluid. The free air could be escaping easily to the case through the unit gaps, since it has very low viscosity.

\subsection{Simulation results}

Three oil models were tested and yielded similar results: the isothermal model, adiabatic and adiabatic added with $0.3 \%$ volumetric air content. While the adiabatic bulk modulus contributed to pressure ripple increase in the simulation, the aeration on its turn decreased the oscillations magnitude.

The three models had provided very similar results. The adiabatic properties increase the pressure oscillations while the air content decreases it, but the magnitude difference of the three models are small. In summary, as long as the hydraulic circuit is a closed circuit and has high pressure to avoid cavitation, neglecting aeration or using the isothermal Bulk modulus should not compromise accuracy.

Isothermal models are used in lumped and distributed parameters simulation as being a good approximation for the adiabatic fluid behavior. The results of this study shown in Figs. 9 and 10 corroborate this assumption.

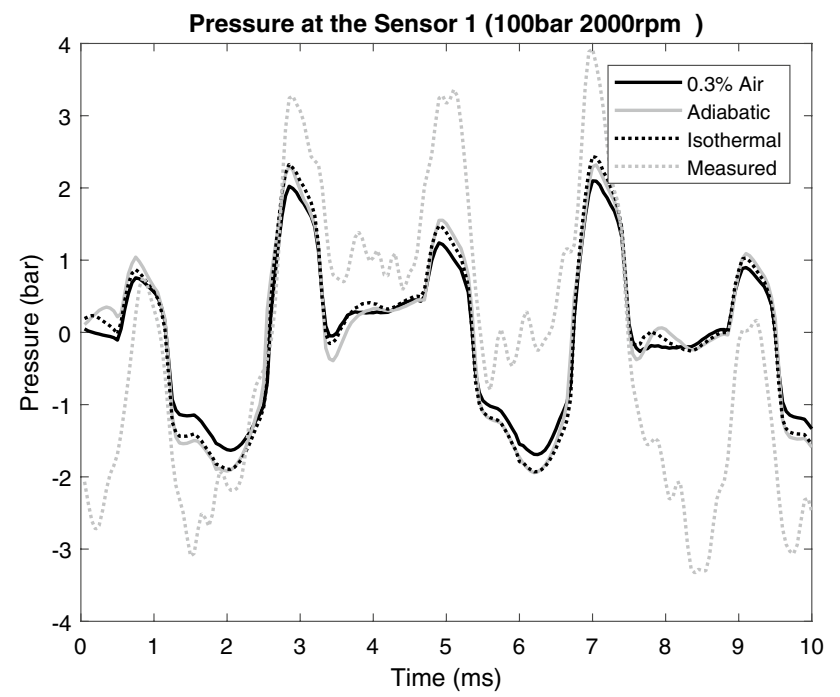

Fig. 9 Oil models results vs measurement at sensor 1 for test $1(100$ bar, unit 1 speed $=2000 \mathrm{rpm}$, unit 2 speed $=920 \mathrm{rpm}$ )
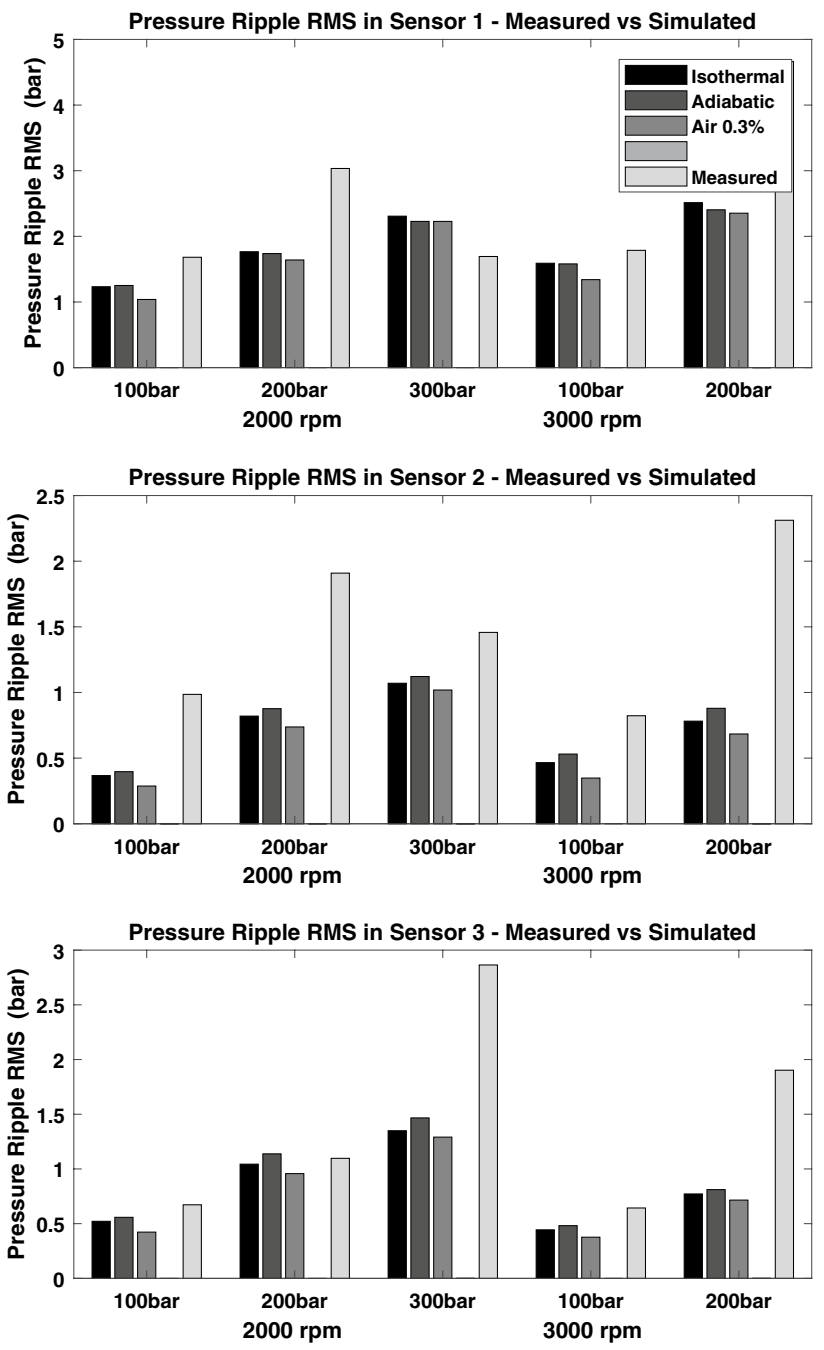

Fig. 10 Pressure ripple RMS values for simulated models compared to the measured data for all five operation conditions at the three sensor positions

\section{Varying line parameters influence}

\subsection{Model discretization}

The MOC approach for calculating pressure ripple simulates varying parameters in a line by calculating a variable wave speed through the length of the line. A system with numerous minor changes in properties may be approximated by the use of "equivalent length" that spans minor discontinuities [14]. In order to compensate for the fixed time step, each node has its respective equivalent length calculated according to the distance the wave will travel during one-time step. Figure 11 represents this discretization. The chosen time step for the line model was equivalent to 10 microseconds. For better simulation stability, the oil properties were calculated using the mean pressure of the line though its length as a reference. 


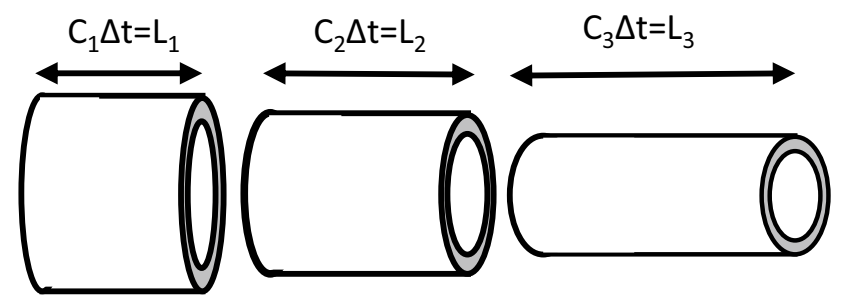

Fig. 11 Approximation for variable-property series system; length of a node is adjusted according to the speed of sound and fixed time step

The steady friction terms are calculated at each line node $j$ along the pipe and at every time steps for higher fidelity of the model. The steady component of the friction in time-domain is the shear stress with permanent components given by (22).

$\tau_{\text {steady }, j}=\frac{1}{8} \cdot \rho \cdot f_{j} v_{j} \cdot\left|v_{j}\right|$

Where the $v_{j}$ terms are the speed of flow at each node and $f_{\mathrm{j}}$ is the Darcy-Weissbach friction factor at each node. The friction factor is calculated based on empirical data. Equation (23) shows friction for laminar flow behaves inversely proportional to the Reynolds number Re. Equation (24) describes the turbulent flow friction factor which is less sensitive to Reynolds number variation:

$f_{l, j}=\frac{64}{\operatorname{Re}_{j}}$

$f_{t, j}=\frac{0.316}{\operatorname{Re}_{j}^{0.25}}$

The friction factor $f$ can also be strongly frequency dependent as the wall shear stress is dependent not only on the mean flow speed but also on the flow acceleration. The unsteady friction model is based on a modified convolution integral solution and verified by empirical data and developed by Schohl [39]. Simplified weighting functions were used to determine the transient friction parameters acting on the fluid flow where $m_{\mathrm{i}}$ is a series of coefficients and $v_{\mathrm{ij}}$ is an updated value representing change in velocity at previous time steps for each (25).

$\tau_{\text {unsteady }, j}=\frac{2 \cdot \rho \cdot v_{j}}{r} \sum_{i=1}^{5} m_{i} \cdot y_{i, j}(t)$

The presence of both sharp and smooth curvatures at the line increases the pressure drop in the fluid from the upstream to downstream direction. It was observed that for pressure variations in the millisecond range, which is the pressure ripple range, the radial inertia is insignificant
Table 5 Simulation Models

\begin{tabular}{llll}
\hline Model & $\begin{array}{l}\text { Material } \\
\text { Change }\end{array}$ & $\begin{array}{l}\text { Enhanced } \\
\text { Friction }\end{array}$ & $\begin{array}{l}\text { Varying } \\
\text { Diameter }\end{array}$ \\
\hline 1 & No & No & No \\
2 & Yes & Yes & No \\
3 & Yes & Yes & Yes \\
\hline
\end{tabular}

[40]. Further, this observation was empirically demonstrated by Wiggert [41] which simplified a line with high curvature for a 4-equation model of the characteristics method to predict with good accuracy the pressure ripple propagation in a curved line.

However, in a composite system, the pressure drop can change the behavior of the flow oscillations generated by the hydraulic units, which in turn can alter the pressure oscillations contained in the line. The pressure drop through a curvature can be described as equivalent to pressure drop in a straight tube of greater length. The ratio between these lengths is given by an empirically obtained factor used in water hydraulics [42]. Thus, the pressure drop can be calculated in (25) and the factor $K_{f}$ is used in equation (21) to adjust the pressure in each node of the line.

$p_{\text {Loss }}=K_{f} \cdot f \frac{L \cdot \rho \cdot v^{2}}{2 D}$

As summarized in table 5, three different versions of the line model were simulated to evaluate the impact of the varying parameters of the duct in a hydraulic line. Model 1 considered the line as pure steel and a constant inner diameter of $19 \mathrm{~mm}$. In model 2 the constant diameter was kept but the duct line considers both segments of steel and hydraulic hose according to the actual experimental setup. Pressure drop from the line curvatures was also added to model 2 .

Figure 12 shows the measured pressure ripple of all three simulations in the equivalent sensor locations. The developed model predicts divergent pressure ripples at different line locations by selecting the node equivalent to the sensor location on the one-dimensional grid.

Among the models, the largest divergence in results was from model 1 to model 2 . The varying parameter that most influenced the pressure ripple was the enhanced friction which increased high frequency oscillations in the time domain. The inclusion of diameter variation in model 3 did not present relevant differences when compared to model 2 , implying not much sensible to the speed of sound variation between the nodes. The material change of the line also influences mostly the wave speed. 
(a)

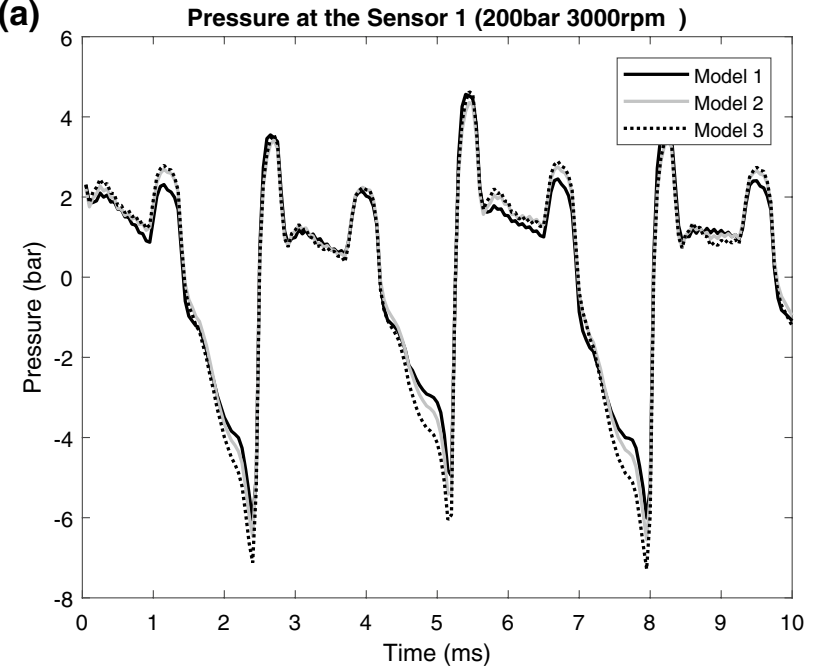

(b)

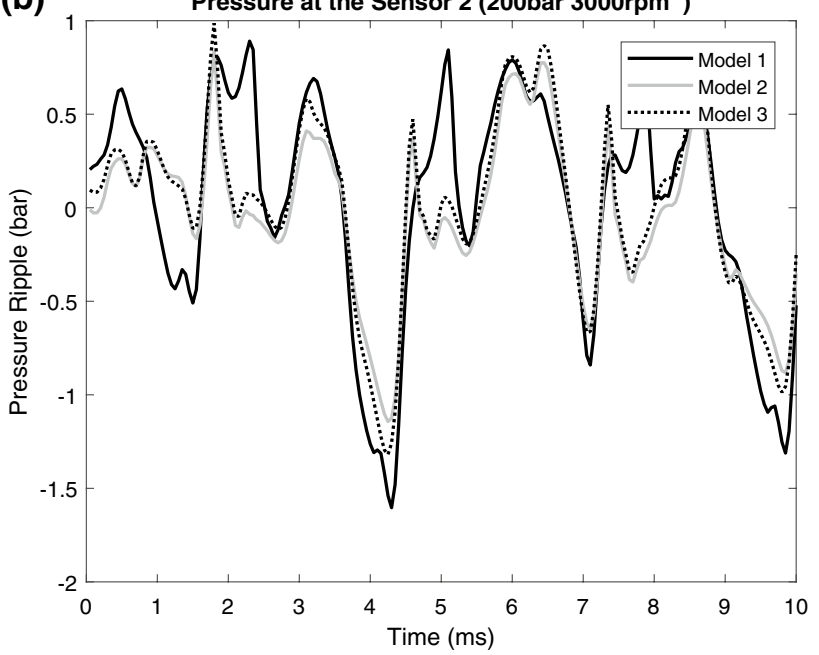

(c)

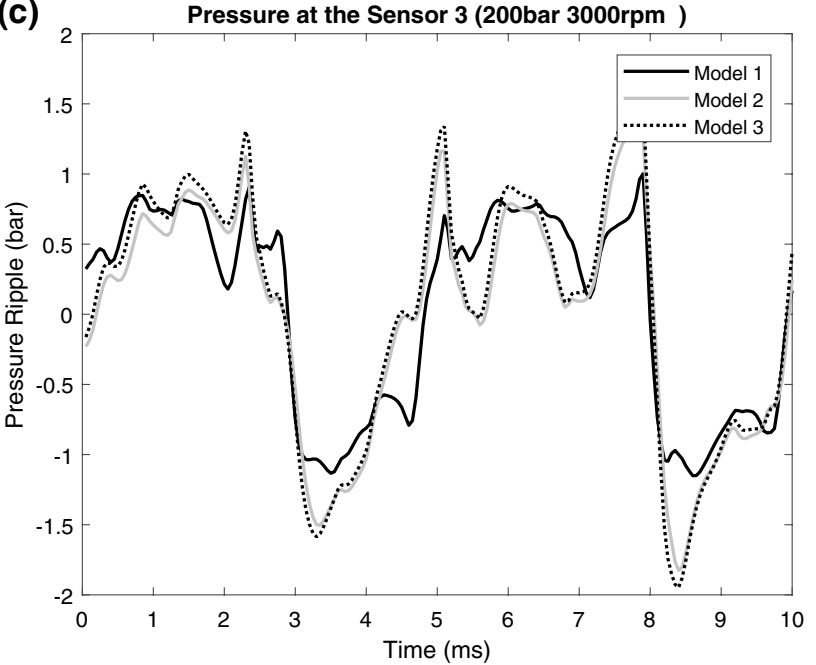

Fig. 12 Measurement vs simulation models Time domain results at 200 bar, unit 1 speed $=3000 \mathrm{rpm}$, unit 2 speed $=1330 \mathrm{rpm}$ for a Sensor 1 b Sensor 2 c Sensor 3
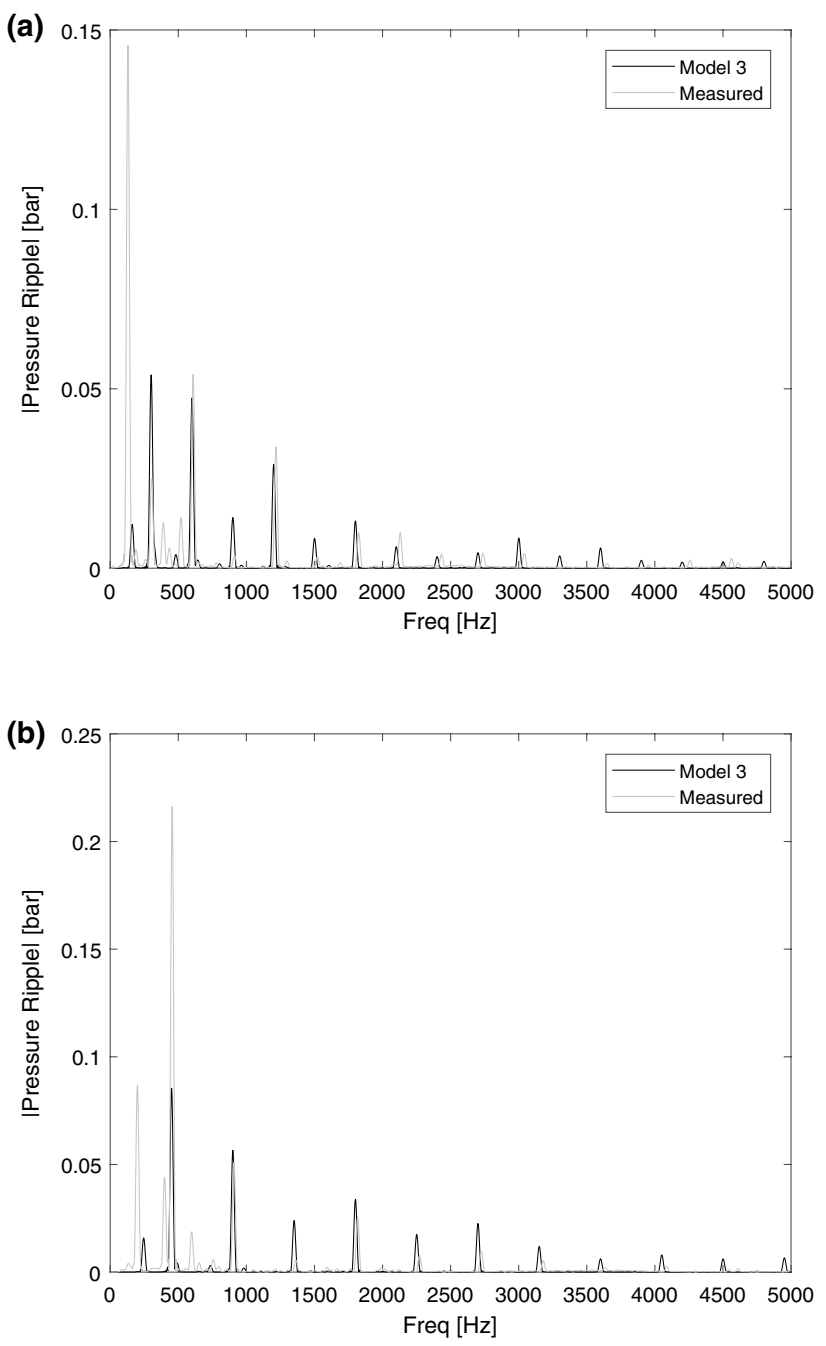

Fig. 13 Sensor 1, frequency domain comparison, measurement versus simulation at a $200 \mathrm{bar}$, unit 1 speed $=2000 \mathrm{rpm}$, unit 2 speed $=930 \mathrm{rpm}$ and $\mathbf{b} 200$ bar, unit 1 speed $=3000 \mathrm{rpm}$, unit 2 speed $=1330 \mathrm{rpm}$

\subsection{Simulation versus measurements results}

The most complete version of the line model (model 3 ) is now compared to the experimental data obtained in the three sensor positions of the transmissions hydraulic line. Figure 13 and 14 compare the frequency domain results for operation conditions $B$ and $E$ on sensor location 1 and 3 respectively for time and frequency domain. As sensor 1 is close to the pumping unit, the simulation captures the harmonic content of unit 1 with some precision up to the $15^{\text {th }}$ harmonic. The first and third harmonic at 300 and 900 $\mathrm{Hz}$ for test $\mathrm{B}$ and 450 and $1350 \mathrm{~Hz}$ for test $\mathrm{E}$ are exceptions.

There is some imprecision on frequency values from measurement to simulation due to inaccurate leakages and speed estimations in the units, especially on the motoring unit. The motoring unit high frequency 


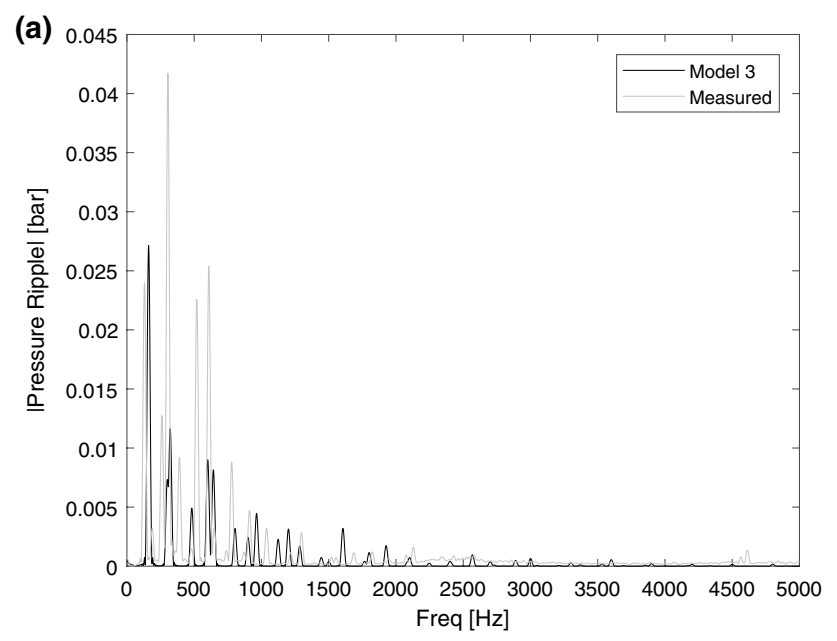

(b)

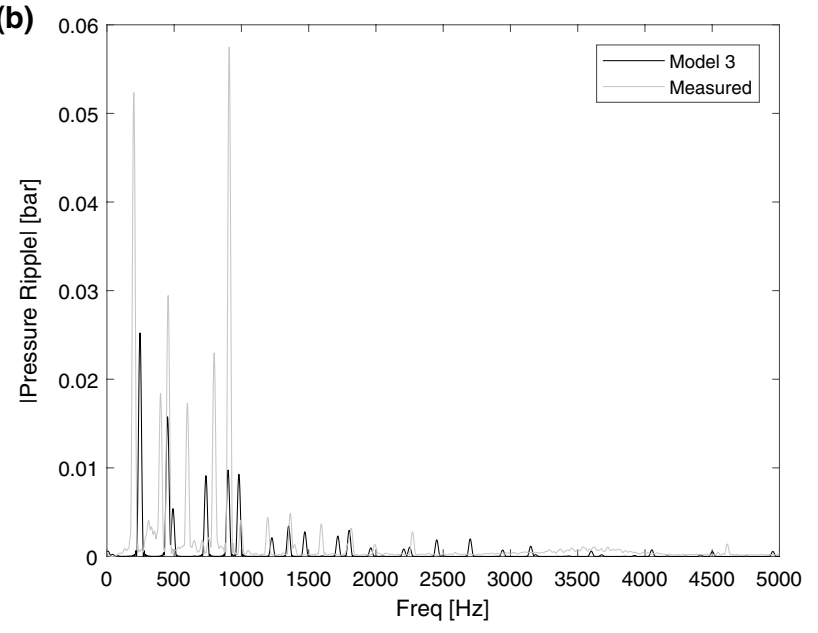

Fig. 14 Sensor 3, frequency domain comparison measurement versus simulation at a 200 bar, unit 1 speed $=2000$ rpm, unit 2 speed $=930 \mathrm{rpm}$ and $\mathbf{b} 200$ bar, unit 1 speed $=3000 \mathrm{rpm}$, unit 2 speed $=1330 \mathrm{rpm}$

content is dissipated through friction damping and even the models with simple friction are capable of capturing this phenomenon. However, the greatest discrepancy from simulation to measurement was first harmonic of the motoring unit at $140 \mathrm{~Hz}$ for test $\mathrm{B}$ and $200 \mathrm{~Hz}$ for test E. Conversely at sensor 3 position, closer to unit 2, the first two harmonics of the motoring unit were captured well, pointing to inaccuracies in the transmission loss of the model.

Figure 15 shows root means square (RMS) value for all five operation conditions. The best matching was in sensor 1 location overall. Sensor 3 is the second best. Basically, the closest a measurement was from a unit, the better was the prediction, which points out for good accuracy from the hydraulic unit model. The line model, however, is still not capable of translating the pressure pulsation down
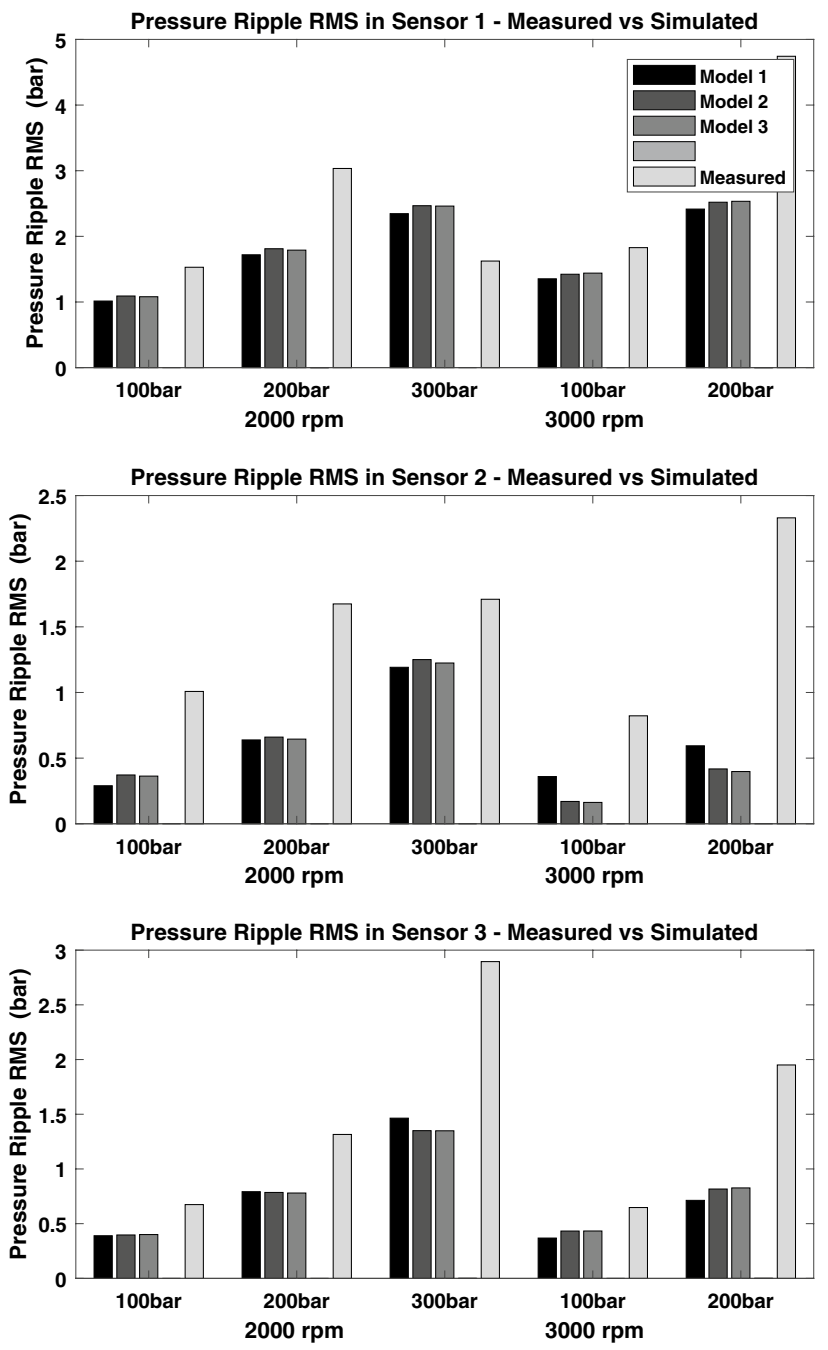

Fig. 15 Pressure ripple RMS values for simulated models compared to the measured data for all five operation conditions at the three sensor positions

the line while capturing every frequency mode alteration in the process.

Overall, the inaccuracy in specific frequencies point to missing boundary conditions and frequency resonant modes. The pipe structural path is a good candidate for these oscillations as axial longitudinal and torsional waves can propagate through the structure and interact with the fluid in many segments of the line. The pipe couplings, on the other hand, are possibly the missing boundary conditions to the line model.

\section{Conclusions}

This research presented the comparison of pressure ripple simulations for a novel hydraulic hybrid architecture and the evaluation of the influence of geometric and material 
parameters on pressure ripple in a hydraulic circuit. Three MOC based line model versions and three fluid models, with different levels of sophistication, were simulated and compared to evaluate the impacts of enhanced friction and diameter variation in hydraulic system. The most sopiticated model was compared to measured data at five operation conditions. The goal was to evaluate if this new line modelling approach would give a direction where non-characterized and not assembled systems could be simulated beforehand and designed for FBNS reduction.

An experiment was designed where a recently developed hydraulic architecture was built. The hydraulic line of the circuit had discontinuities and parameter variations, rather than a straight line controlled experiment for measuring pressure ripple. As an exception, one segment of the line was designed to test a technique for measuring the speed of sound and calculate fluid aeration.

The varying parameters of the line and fluid influenced the pressure ripple propagation at the hydraulic line. However, the differences between the models which neglect these parameters and the ones which include these parameters were not too significant. The pressure ripple magnitude of all simulations was similar to experiment and had a small deviation when compared to the measured pressure ripples.

The modelling approaches showed great discrepancy in accuracy for capturing different frequencies responses present in the experiment. In some situations, the simulations were able to reproduce with good fidelity even high frequency content generated by the units, however, some targeted frequencies had diverged greatly from simulation to measurement. These frequencies had usually high energy content compared to the total pressure oscillation and in many cases also compromised the pressure RMS evaluation.

The disparity between good predictions in some frequency bands and bad forecasts in others, is evidence that there are some modal contents and boundary conditions the current models are not considering. None of the parameters evaluated in this paper were able to explain this phenomenon.

Therefore, a good candidate for controlling these variables is line structure. Line structure modal response, propagating axial longitudinal and rotational waves and finally structure borne noise excitations from units are serious candidates for the generation of the currently unpredicted frequency components. The complexity of realistic hydraulic systems is high and in order to predict noise source propagation without an empirical characterization and unbuilt circuits, better models are still needed.

A good topic for further improvement in this research is integrating the current fluid line model with a conduit structural finite element model.
Acknowledgements This work is supported by Conselho Nacional de Desenvolvimento Cientfico e Tecnolgico (Grant: GDE 207282/2014-5) by funding the first author.

\section{Compliance with ethical standards}

Conflict of interest The authors declare that they have no conflict of interest.

\section{References}

1. Edge K A (1999) Designing quieter hydraulic systems some recent developments and contributions, simulation modelling practice and theory. In: Forth JHPS international symposium, pp 3-27. ISBN 4-931070-04-3

2. Fiebig W (2007) Location of noise sources in fluid power machines. Int J Occup Saf Ergon 13(4):441-450

3. Johansson A (2005) Design principles for noise reduction in hydraulic piston pumps simulation, optimisation and experimental verification, PhD Thesis Linkping: Linkpings Tryckeri, Sweden

4. Devendran RS, Vacca A (2013) Optimal design of gear pumps for exhaust gas after treatment applications. Simul Model Pract Theory 38:1-19

5. Zanetti-Rocha L, Gerges SNY, Johnston DN, Arenas JP (2013) Rotating group design for vane pump flow ripple reduction. Int J Acoust Vib 18(4):192-200

6. Akers A, Gassman M, Smith R (2006) Hydraulic power system analysis. CRC Press, Boca Raton

7. Johnston N (2012) The transmission line method for modelling laminar flow of liquid in pipelines. In: Proceedings of the institution of mechanical engineers, Part I: Journal of Systems and Control Engineering, vol 226, no 5, pp 586-597

8. Johnston N, Pan M, Kudzma S (2014) An enhanced transmission line method for modelling laminar flow of liquid in pipelines. In: Proceedings of the institution of mechanical engineers. Part I: Journal of Systems and Control Engineering vol 228, no 4, pp 193-206

9. Manhartsgruber B (2019) H2-Optimal low order transmission line models. In: Proceedings of the ASME/BATH (2019) symposium on fluid power and motion control, FPMC2019-1688. LongBoat Key, FL, USA

10. Kim KH, Jang JS, Jung DS, Kim HE (2005) Reduction of pressure ripples using a parallel line in hydraulic pipeline. Int J Autom Technol 6(1):65-70

11. Kojima E, Ichiyanagi T (2000) Research on pulsation attenuation characteristics of silencers in practical fluid power systems. Int J Fluid Power 1(2):29-38

12. Kojima E, Shinada M (1986) Characteristics of a fluid borne noise generated by a fluid power pump. Bull JSME 29(258):430-433

13. Watton J, Tadmori MJ (1988) A comparison of techniques for the analysis of transmission line dynamics in electrohydraulic control systems. J Appl Math Model 12:457-466

14. Wylie EB, Streeter VL (1978) Fluid transients, 1st edn. MCGrawHill, New York

15. Vitkovsky J, Lambert M, Simpson A (2000) Advances in unsteady friction modelling in transient pipe flow. In: The 8th international conference on pressure surges. Ljubljana, Slovenia

16. Zarzycki Z, Kudzma S (2004) Simulations of transient flow in liquid lines using time-dependent frictional losses. In: 9th International conference on pressure surges, BHR Group, pp 439-455 
17. Adamkowski A, Lewandowski M (2006) Experimental examination of unsteady friction models for transient pipe flow simulation. J Fluids Eng 128(6):1351-1363. https://doi. org/10.1115/1.2354521

18. Klop R, Ivantysynova M (2008) Influence of line length concerning noise source generation in hydrostatic transmissions. Technical paper, SAE international, ISSN: 0148-7191, e-ISSN: 26883627 https://doi.org/10.4271/2008-01-2722

19. Klop RJ (2010) Investigation of hydraulic transmission noise sources. Purdue University, West Lafayette, IN PhD Thesis

20. Maillard J (1998) Active control of pressure pulsations in piping systems. Research Report, University of Karlskrona/Ronneby, Ronneby, Sweden

21. Harrison AM (1997) Reduction of axial piston pump pressure ripple. PhD thesis, University of Bath, United Kingdon

22. Dodson JM, Dowling DR, Grosh K (1998) Experimental investigation of quarter wavelength silencers in large scale hydraulic systems. Noise Control Eng J 46(1):15-22

23. Weddfelt K, Larsson P, Palmberg JO (1987) Investigation of the performance of expansion chamber attenuators by means of simulations and measurements. In: 16th EASTED international conference identification, modelling and simulation, pp 22-24, Paris, France

24. Kartha SC (2000) Active, passive and active/passive control techniques for reduction of vibrational power flow in fluid filled pipes. MS Thesis, Virginia Polytechnic Institute and State University, USA

25. Zygmunt Kudma, Micha Stosiak (2013) Reduction of infrasounds in machines with hydrostatic drive. Acta Bioeng Biomech 15(2):51-64

26. Chaudhry M H (2014) Applied hydraulic transients, 3rd Edition. Springer, New York. 978-1-4614-8537-7. https://doi. org/10.1007/978-1-4614-8538-4

27. Wieczorek U, Ivantysynova M (2002) Computer aided optimization of bearing and sealing gaps in hydrostatic machinesthe simulation tool caspar. Int J Fluid Power 3(1):7-20

28. Borghi M, Milani M, Paltrinieri F, Zardin B (2005) Pressure transients in external gear pumps and motors meshing volumes, Rosemont, IL: T, Technical paper SAE International, SP-1989. 20053619

29. Wilhelm S (2015) Modeling, analysis, and experimental investigation of a variable displacement linkage pump. University of Minnesota, Minneapolis, MN PhD Thesis

30. Sprengel M, Bleazard T, Haria H, Ivantysynova M (2015) Implementation of a novel hydraulic hybrid powertrain in a sports utility vehicle. IFAC-PapersOnLine, 48-15, pp 187-194
31. Williams K, Ivantysynova M (2019) Approximate stochastic differential dynamic programming for hybrid vehicle energy management. J Dyn Syst Meas Control 141(5):051003. https://doi. org/10.1115/1.4042253

32. Ding D, Kalbfleisch K, Ivantysynova M (2016) Development of data analytics tools for acoustic measurement of positive displacement machines. In: The summer undergraduate research fellowship (SURF) symposium. Purdue University, West Lafayette

33. Gholizadeh H (2013) Modeling and experimental evaluation of the effective bulk modulus for a mixture of hydraulic oil and air. University of Saskatchewan, Saskatoon PhD Thesis

34. Hayward ATJ (1970) How to estimate the bulk modulus of hydraulic fluids. Hydraul Pneum Power 16(181):28-40

35. Kim S, Murrenhoff H (2012) Measurement of effective bulk modulus for hydraulic oil at low pressure. J Fluids Eng 134(2):021201. https://doi.org/10.1115/1.4005672

36. Singhal AK, Athavale MM, Li H, Jiang Y (2002) Mathematical basis and validation of the full cavitation model. J Fluids Eng Trans ASME 124(3):617-624

37. Belamri T, Zwart P J, Gerber A G (2004) A two-phase flow model for predicting cavitation dynamic. In: ICMF 2004 international conference on multiphase flow Yokohama, Japan, May 30 -June 3, 2004 Paper No. 152

38. Huayong Y, Bin F, Guofang G (2011) Measurement of effective fluid bulk modulus in hydraulic system. J Dyn Syst Meas Control

39. Schohl G (1993) Improved approximate method for simulating frequency-dependent friction in transient laminar flow. J Fluids Eng 115:420-424

40. Walker JS, Phillips JW (1977) Pulse propagation in fluid filled tubes. ASME J Appl Mech 44(1):31-35. https://doi. org/10.1115/1.3424009

41. Wiggert DC, Otwell RS, Hatfield FJ (1985) The effect of elbow restraint on pressure transients. J Fluids Eng 107:402-406

42. Menon ES (2004) Piping calculations manual. McGraw-Hill, New York

Publisher's Note Springer Nature remains neutral with regard to jurisdictional claims in published maps and institutional affiliations. 